\title{
GEOPROCESSAMENTO APLICADO À AVALIAÇÃO QUANTITATIVA DA GEODIVERSIDADE NA ÁREA DO GEOPARQUE ASPIRANTE SERIDÓ - RN
}

\author{
GEOPROCESSING APPLIED TO THE QUANTITATIVE EVALUATION OF GEODIVERSITY IN \\ THE AREA OF SERIDÓ ASPIRING GEOPARK - RN
}

\author{
Matheus Lisboa Nobre da SILVA ${ }^{1}$, Marcos Antonio Leite do NASCIMENTO², \\ Kátia Leite MANSUR ${ }^{3}$ \\ ${ }^{1}$ Universidade Federal do Rio de Janeiro. Museu Nacional. E-mail: nobre.mt@gmail.com \\ ${ }^{2}$ Universidade Federal do Rio Grande do Norte. Departamento de Geologia. E-mail: marcos@geologia.ufrn.br \\ ${ }^{3}$ Universidade Federal do Rio de Janeiro. Instituto e Geociências. E-mail: katia@geologia.ufrj.br
}

\author{
Introdução \\ Área de Estudo \\ Material e Método \\ Resultados e Discussão \\ Conclusão \\ Agradecimentos \\ Referências
}

\begin{abstract}
RESUMO - Em paralelo com a biodiversidade, os elementos abióticos da natureza, ou geodiversidade, devem ser protegidos e conservados de forma a manter as condições ambientais. A seleção de elementos e locais de maior importância é parte da gestão territorial e perpassa pela definição de valores da geodiversidade. Estes podem ser definidos qualitativa ou quantitativamente. O geoprocessamento disponibiliza ferramentas e técnicas que podem fornecer valores numéricos mais objetivos, embasando o processo de tomada de decisão. Neste trabalho, realizado na área do Geoparque Aspirante Seridó, foi aplicada uma metodologia com o uso de quadrículas para a contagem de elementos de acordo com as cartas temáticas de geologia, geomorfologia, pedologia, hidrografia e recursos minerais. O objetivo principal é obter uma avaliação quantitativa da geodiversidade da área de estudo, utilizando softwares livres e correlacionando a avaliação com os elementos observados em campo. Obteve-se o índice de geodiversidade, variando de valores muito baixos (1-3) a muito altos (12-14). Os resultados da avaliação quantitativa têm boa correlação com os geossítios definidos no âmbito do Geoparque, o que justifica a inserção destes locais na gestão territorial, porque representam áreas de alta geodiversidade, exemplos da importância da diversidade abiótica para a natureza integrada com a comunidade local.
\end{abstract}

Palavras-chave: Geodiversidade, geoprocessamento, quantificação.

\begin{abstract}
In parallel with biodiversity, abiotic elements of nature, or geodiversity, must be protected and preserved in order to maintain environmental conditions. The selection of elements and places of major importance is part of territorial management and goes through the definition of geodiversity values. These can be defined qualitatively or quantitatively. Geoprocessing provides tools and techniques that can provide more objective numerical values, underpinning the decision-making process. This work was carried out in the area of the Seridó Aspiring Geopark. The main objective is to obtain a quantitative assessment of the geodiversity of the study area, using free software and correlating the assessment with the elements observed in the field. A methodology was applied with the use of squares for the counting of elements according to the geology, geomorphology, pedology, hydrography and mineral resources. The geodiversity index was obtained, ranging from very low (1-3) to very high (12-14). The results of the quantitative evaluation have a good correlation with geosites defined in the Geopark, which justifies the insertion of these sites in territorial management, because they represent areas of high geodiversity, examples of the importance of the abiotic diversity to the nature integrated with the local community.
\end{abstract}

Keywords: Geodiversity, geoprocessing, quantification.

\section{INTRODUÇÃO}

A definição de valores é etapa fundamental na elaboração de ações de proteção da natureza, uma vez que fornece embasamento para a hierarquização de prioridades para conservação. Assim, o estabelecimento dos locais de maior valor fornece subsídio para a gestão e manejo ambiental sustentáveis. Esta afirmativa também é válida para os estudos da geodiversidade, entendida como o conjunto de elementos abióticos da natureza, tais como minerais, rochas, relevo, solos, água, entre outros.

Como componente essencial da diversidade natural do planeta, a geodiversidade possui importância fundamental para a vida na Terra, para o estabelecimento e manutenção do equilíbrio e processos naturais. Portanto, é essencial que os estudos ambientais também sejam voltados para a conservação dos elementos abióticos do meio ambiente, assim como já é feito para a biodiversidade.

A avaliação da geodiversidade, sobretudo de forma qualitativa, possui por vezes um caráter subjetivo e de difícil compreensão, sendo extremamente dependente do ponto de vista do 
pesquisador e até mesmo do nível de conhecimento científico possível para a área. Por isso, métodos de análise quantitativa, que empreguem elementos concretos, vêm ganhando força no desenvolvimento dos estudos dos elementos abióticos do meio ambiente.

A maioria dos métodos quantitativos procura representar de forma matemática ou gráfica a riqueza da geodiversidade de uma região, ou índices de geodiversidade, baseando-se na variedade de elementos e distribuição geográfica, por exemplo.

Nesta perspectiva, o trabalho de Kozlowski (2004) mostra uma proposta de delimitação de classes numa avaliação da geodiversidade. O autor elenca cinco classes (muito alta, alta, moderada, baixa e muito baixa) para a classificação da diversidade abiótica a partir da análise de quatro parâmetros: relevo, solos, água de superfície e estrutura da paisagem.

Reynard et al. (2007) definem critérios de avaliação de geomorfossítios através da análise de valores científico, ecológico, estético, cultural e econômico. Definindo valores de 0 a 1 que correspondem, respectivamente, a critério inexistente a muito alto, os autores procuram refletir, de forma matemática, a diversidade abiótica de um local pela integridade de seus elementos, representatividade, raridade, entre outras informações. Por outro lado, Serrano \& Ruiz-Flaño (2007) estabelecem uma equação para definir o índice de geodiversidade de uma região a partir da análise da geomorfologia local. Assim, os autores propõem que esta riqueza é proporcional ao número de elementos existentes numa região e ao índice de rugosidade, que representa a heterogeneidade morfológica local.

$\mathrm{O}$ uso das técnicas de geoprocessamento tem se mostrado uma forma de automação das análises quantitativas em estudos da geodiversidade, a exemplo do trabalho de Jačková \& Romportl (2008), que se beneficia do geoprocessamento ao estabelecer células em um grid sobre a área analisada. Cada célula representa uma pequena parte da área e a variedade e diversidade de elementos dentro de seus limites corresponde à riqueza da geodiversidade local.

Zwolinski et al. (2018) fazem um apanhado geral sobre as metodologias de avaliação da geodiversidade e relatam que a álgebra cartográfica tem evoluído para a interpretação da relação intrínseca entre a diversidade abiótica e a biodiversidade. Contudo, a utilização das geotecnologias esbarra na limitação da qualidade dos dados, visto que são poucas áreas, sobretudo no Brasil, que possuem vasta cartografia de detalhe.

Rodrigues \& Bento (2018) indicam que o uso de métodos cartográficos de avaliação da geodiversidade tornou-se importante para a gestão territorial, reconhecendo a integralidade da natureza e seus elementos e "desmistificando a imagem de um ambiente pela metade e no qual apenas os elementos bióticos teriam valor [...]”.

Em relação à área de estudo deste trabalho, Geoparque Aspirante Seridó (Rio Grande do Norte), pode-se afirmar que se trata de uma região com um notável patrimônio geológico, cuja proposta de criação de geoparque surgiu com o trabalho de Nascimento \& Ferreira (2012). Estes autores e, posteriormente, Medeiros (2015) e Silva (2018), se debruçaram sobre o inventário da geodiversidade local, elencando, principalmente, seus valores qualitativos. São estes trabalhos que sustentam cientificamente a importância da diversidade abiótica da região. Contudo, há uma necessidade de definição de valores quantitativos, com mínimo de subjetividade possível, para fortalecer as ações de geoconservação.

Neste contexto e a partir da importância de avaliação da diversidade abiótica, além da possibilidade de uso de recursos de geoprocessamento, sobretudo com ferramentas de software livre, que permite a popularização dos Sistemas de Informação Geográfica, fez-se neste trabalho a quantificação da geodiversidade na área do Geoparque Aspirante Seridó, com o objetivo de fornecer suporte às tomadas de decisão referentes a ações de conservação da natureza abiótica.

\section{ÁREA DE ESTUDO}

O Geoparque Aspirante Seridó está localizado no interior do Rio Grande do Norte, extremo nordeste do Brasil (Figura 1), numa área de 2.802 $\mathrm{km}^{2}$, distante $180 \mathrm{~km}$ da capital potiguar, Natal, percorridos ao longo das rodovias federal BR-304 e estadual $\mathrm{RN}-226$. Cortando o território estão ainda as rodovias BR-104, BR-427, RN-041 e RN086. O primeiro município acessado pela estrada, a partir de Natal, é Currais Novos. Ao norte ficam as cidades de Lagoa Nova e Cerro Corá e ao sul Acari, Carnaúba dos Dantas e Parelhas. A distância entre os municípios extremos da área não ultrapassa 100 


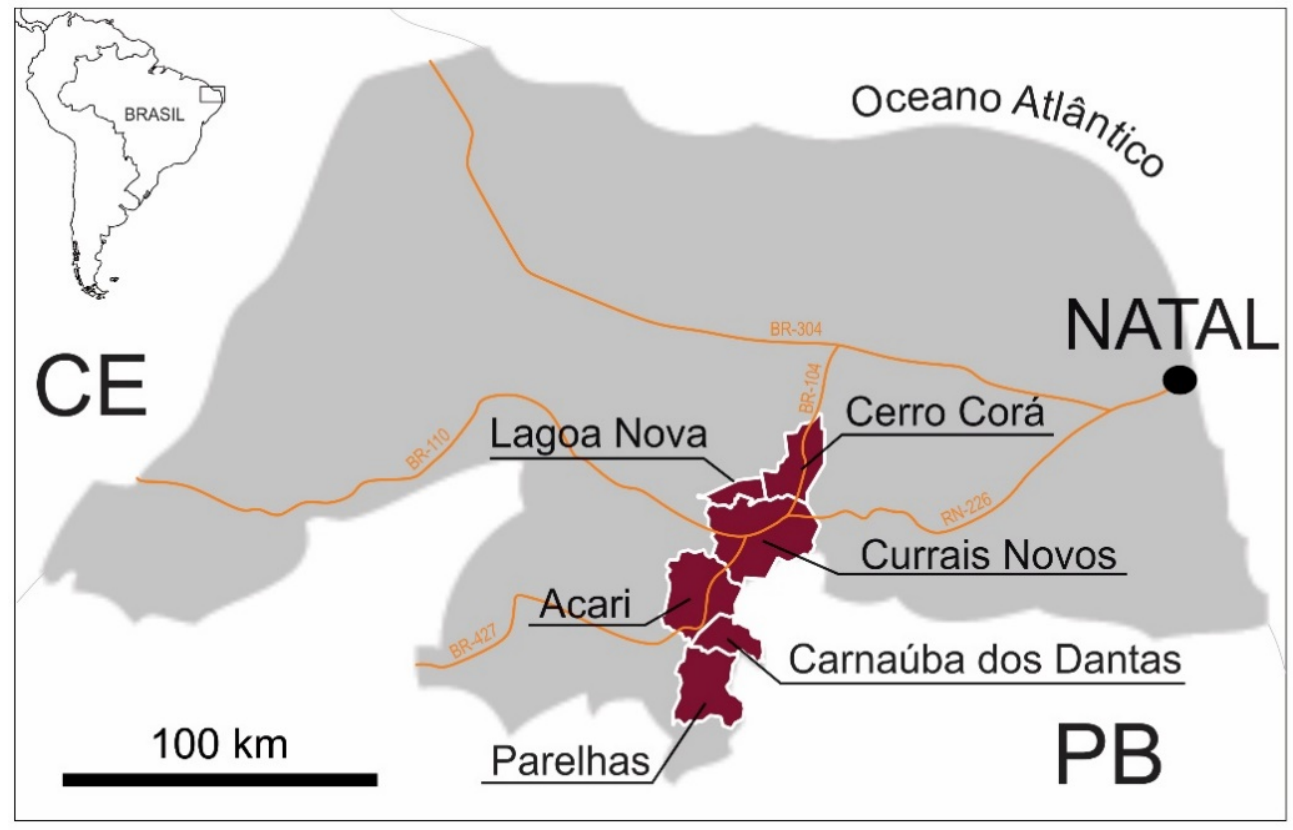

Figura 1 - Mapa de localização simplificado do Geoparque Aspirante Seridó.

O clima local é influenciado pela Zona de Convergência Intertropical do Atlântico, principal sistema controlador das precipitações na região do Seridó, que, em geral, são concentradas na chamada quadra chuvosa, de maio a agosto.

Predomina na área o subtipo climático semiárido forte, com precipitações variando entre 400 e 900 mm/ano (Diniz \& Oliveira, 2015). A temperatura média anual é de $28,3^{\circ} \mathrm{C}$ (INMET, 2018).

A vegetação da área de estudo é englobada pelo Bioma Caatinga, com formações vegetais lenhosas, de porte baixo ou médio tipicamente caducifólio de caráter xerófilo, com grande quantidade de plantas espinhosas, de esgalhamento baixo, com muitas cactáceas e bromeliáceas. São espécies típicas da área: jurema preta, faveleira, pinhão-branco, mufumbo, imburana, juazeiro, xiquexique, macambira, coroa-de-frade (IDEMA, 2009).

$\mathrm{O}$ relevo do Seridó possui uma origem poligenética, com formação de depressões interplanálticas e intermontanas semiáridas, revestidas por diferentes tipos de caatinga e pontilhadas por inselbergs (Diniz \& Oliveira, 2015). De sul a norte, observa-se a presença de compartimentos da Depressão Sertaneja, morros, serras baixas, planaltos, planícies, escarpas de serra, chapadas, platôs e colinas dessecadas.

Os terrenos da região do Seridó potiguar são formados por rochas ígneas e metamórficas, em geral impermeáveis, o que dificulta a infiltração e o acúmulo de água em subsuperfície, possibilitado apenas em fraturas nestas litologias ou nos terrenos sedimentares da Serra de Santana (Diniz \& Oliveira, 2015).

Os rios são, em sua maioria, intermitentes, mas por vezes se apresentam perenizados pela ação antrópica. A área de estudo é compreendida pelo sistema hidrográfico Piancó-Piranhas-Açu, mais especificamente na Bacia Hidrográfica PiranhasAçu, composta pelos rios Seridó, Acauã e Salgado. Destacam-se os açudes Dourado, Gargalheiras e Boqueirão (Nascimento \& Ferreira, 2012; Diniz \& Oliveira, 2015).

O contexto geológico da área de estudo é referente ao Domínio Rio Piranhas-Seridó da Subprovíncia Setentrional da Província da Borborema, esta última definida por Almeida et al. (1977) como um sistema de dobramentos desenvolvido ao longo do Ciclo Brasiliano.

Localmente, podem-se distinguir oito agrupamentos geológicos distintos, que datam desde o Paleoproterozoico ao Recente. O embasamento é composto por rochas metamórficas de alto grau (Complexo Caicó), que é sobreposto por supracrustais neoproterozoicas (Grupo Seridó).

Há ocorrências de magmatismos intrusivos e extrusivos no Ediacarano, Cambriano, Cretáceo Inferior e Paleógeno. O registro geológico é completado por arenitos, conglomerados do Neógeno, além de coberturas quaternárias. A figura 2 mostra o mapa geológico com as principais unidades encontradas na área do Geoparque Aspirante Seridó. 


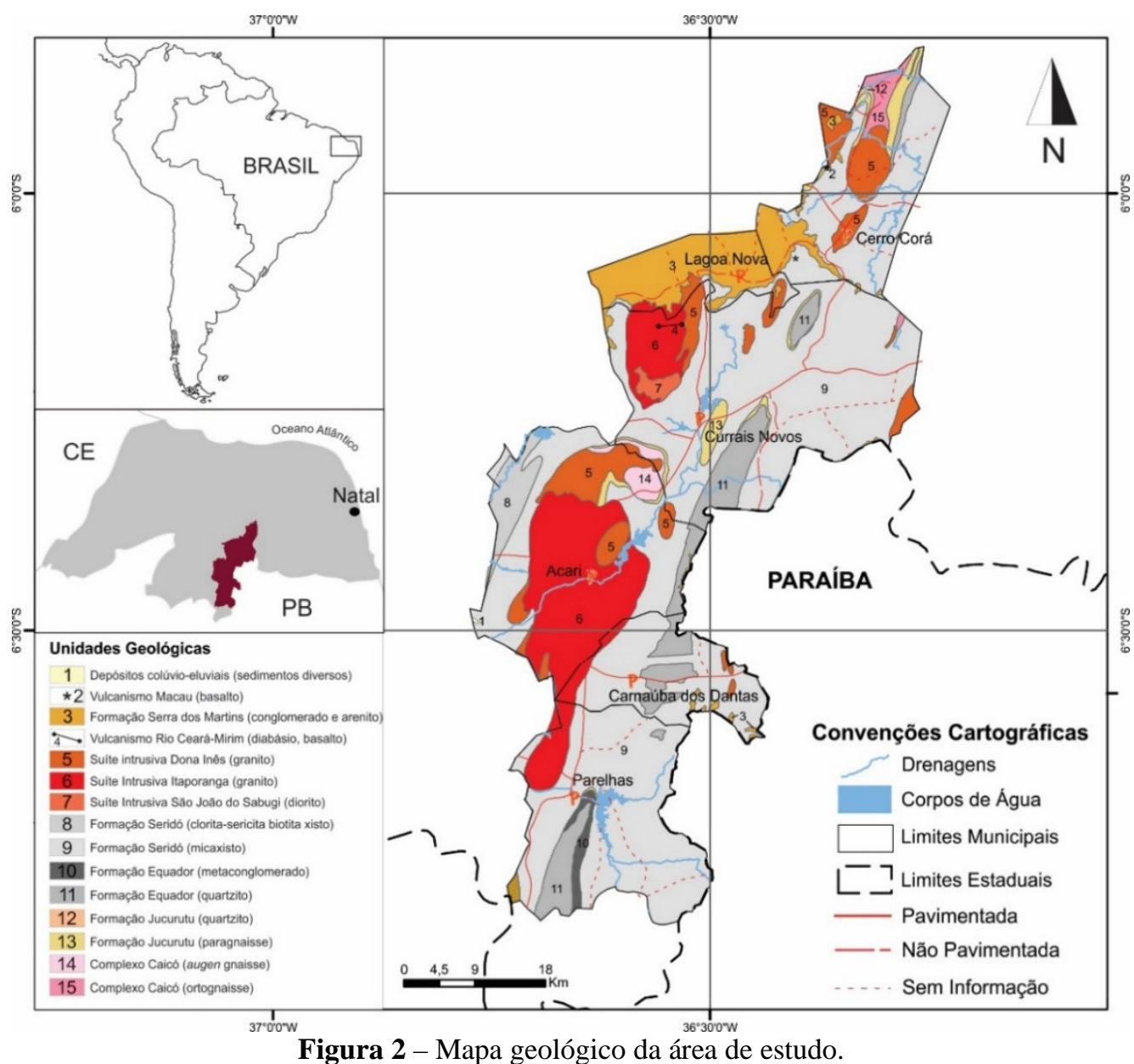

Após uma década desde o início dos estudos sobre a implementação de um geoparque nesta região do nordeste brasileiro, em 2019, o Geoparque Seridó foi oficialmente reconhecido

\section{MATERIAL E MÉTODO}

Para fazer a avaliação quantitativa da geodiversidade na área de estudo, foi empregado neste trabalho o método proposto por Pereira et al. (2013), que lança mão de técnica baseada na geração de um grid regular formado por polígonos sobre cada mapa temático utilizado como fonte cartográfica. O número de elementos internamente a cada polígono representa o valor, ou subíndice da geodiversidade.

Esta técnica é, atualmente, uma das mais utilizadas para a definição de valores quantitativos da geodiversidade por geoprocessamento. São exemplos de trabalhos que já fizeram uso desse método em estudos no Brasil: Arruda \& Barreto (2015), Silva et al. (2015), Araújo \& Pereira (2016) e Santos et al. (2017). Para o processamento dos dados, foi utilizado o software Open Source QGIS 3.0.2, de forma a comprovar a eficiência dos softwares livres em estudos das geociências. As fontes cartográficas possuem dados de geologia - pela UNESCO como Geoparque Aspirante. É, portanto, atualmente, um candidato à Rede de Geoparques Mundiais (Global Geoparks Network, GGN)

1:500.000 (Angelim et al., 2006), geomorfologia - 1:500.000 (Diniz et al., 2017), pedologia 1:250.000 (Base de dados do IBGE), hidrografia - 1:500.000 (Angelim et al., 2006) e recursos minerais - 1:500.000 (Angelim et al., 2006). Todos os materiais utilizados são dados vetoriais, apresentados sob a forma de polígonos fechados ou de informações com representação pontual. Todos os mapas foram construídos sob o sistema geodésico WGS 1984, com coordenadas geográficas.

A situação ideal para o uso deste método é a utilização de mapas de mesma escala e com o maior nível de detalhamento possível, porém esta situação raramente é alcançada, principalmente no estado do Rio Grande do Norte, em que há carência de mapeamento, sobretudo em nível de detalhe. Assim, a escala definida para este trabalho foi a de 1:500.000, que corresponde ao menor nível de detalhe dos planos de informação utilizados. Os dados de pedologia possuem 
escala de 1:250.000, com maior nível de detalhe comparativamente.

A definição da malha de análise seguiu a proposta de Pereira et al. (2013). A área total deste trabalho é de $2.802 \mathrm{~km}^{2}$ e para a aplicação da metodologia foi criada uma malha com polígonos de $2 \times 2 \mathrm{~km}$, de forma a se gerar 824 polígonos para recobrir toda a região. A escolha deste parâmetro para o grid se deu para que as menores ocorrências de corpos d'água do plano de informação de hidrografia fossem incorporadas por uma célula apenas. Malhas de menores distanciamentos poderiam dividir pequenos corpos d’água em duas células enquanto malhas maiores iriam agregar em uma única célula mais de uma ocorrência, elevando a distribuição do índice de hidrografia numa região semiárida, que geograficamente possui carência de ocorrências hidrográficas.

A malha sobreposta aos planos de informação é responsável pela primeira etapa desta metodologia, em que cada quadrícula terá agregado a si um valor que corresponde numericamente à quantidade de tipologias existentes em sua área. Esta operação, de somatória, define os subíndices de cada dado (geologia, geomorfologia, hidrografia, pedologia e recursos minerais), representados por matriz de valores MNT.

A definição de subíndices é importante porque também indica como as ocorrências variam em cada plano de informação. A somatória de todos os subíndices fornece $\mathrm{o}$ índice total de geodiversidade para a região analisada, representando as ocorrências de elementos abióticos de cada quadrícula e de toda a área. Esta operação é realizada através da união, no software, de todos os subíndices, resultando em uma malha final, na qual em cada quadrícula está associado $o$ valor total de índice de geodiversidade para cada ponto.

A exibição final dos dados foi feita a partir da interpolação IDW dos valores. Para isso, os polígonos são convertidos em pontos centrais, que carregam em seus atributos os valores correspondentes do índice de geodiversidade obtido. O resultado da interpolação pode ser classificado, de forma a definir classes, neste trabalho foram definidas cinco classes para o índice de geodiversidade: muito baixo, baixo, intermediário, alto e muito alto.

O resultado final obtido é um mapa coroplético, cujas unidades representam, em suas áreas, índices de geodiversidade diferentes, refletindo uma concentração maior ou menor de elementos da natureza abiótica. Quanto maior o número de elementos numa área, maior a densidade de ocorrência dos elementos e maior, portanto, é o índice de riqueza da região. A figura 3 é uma representação meramente esquemática, simplificando a metodologia de avaliação empregada neste trabalho.

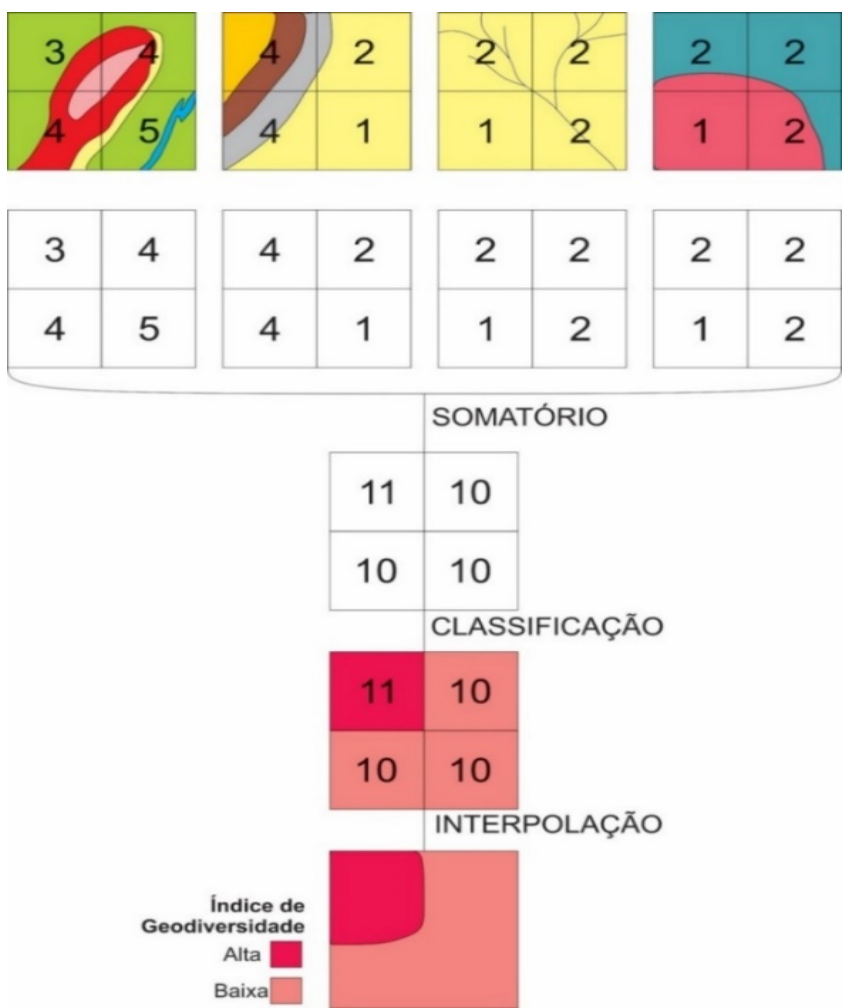

Figura 3 - Representação simplificada do método de análise quantitativa da geodiversidade empregado neste trabalho. 


\section{RESULTADOS E DISCUSSÃO}

A malha sobreposta a cada plano de informação utilizado neste estudo determinou subíndices de geodiversidade representativos de cada dado cartográfico, referente à geomorfologia, hidrografia, litologia, pedologia e ocorrências minerais.

A soma total dos subíndices determina o índice total da geodiversidade da área estudada.

O subíndice de geomorfologia (Figura 4A) apresenta pouca variação, com valores de 0 a 3 , reflexo do domínio principal na região é do Planalto da Borborema, caracterizado por seus relevos movimentados, de superfícies onduladas e inclinadas.

As unidades morfoestruturais no Geoparque são a Depressão Interplanáltica do Acauã e os compartimentos Potengi-Trairi, Seridó, Monte das Gameleiras e Serra de Santana. Esta última, localizada na parte norte da região, é de grande destaque na paisagem local, com platôs que atingem $700 \mathrm{~m}$ de altitude.

A Depressão Sertaneja também é presente na área pela ocorrência da Depressão Interplanáltica Piranhas-Açu e por inselbergs e campos de inselbergs que estão presentes nas porções sul e sudoeste do Geoparque.

Numericamente, os índices mais altos são encontrados, principalmente, na escarpa da Serra de Santana, ao norte da área, no limite da Depressão Sertaneja com o Planalto da Borborema na porção sul e ao longo dos limites da Depressão Interplanáltica do Acauã no centro.

Por estar presente numa região de clima semiárido, a hidrografia na área do Geoparque Aspirante Seridó é incipiente, com apenas alguns corpos de água presentes e pequenos cursos de rios que, por vezes, são classificados como intermitentes.

Isto se reflete no subíndice de hidrografia (Figura 4B), que é o que apresenta valores numericamente mais baixos entre os subíndices de geodiversidade avaliados, os valores mais elevados ocorrem apenas nos locais em que ocorrem os encontros dos poucos corpos d'água mapeados.

A representatividade da litologia no índice de geodiversidade do Geoparque Aspirante Seridó demonstra a variação dos litotipos mapeáveis na região. Os valores mais altos do subíndice (Figura 5A) específico ocorrem, principalmente, ao redor do Granito de Acari ao centro da região, na porção norte da área, onde ocorrem rochas do embasamento, do Grupo Seridó e de granitos, e ao sul, no entorno do açude Boqueirão, em que ocorrem metaconglomerados, xistos e quartzitos do Grupo Seridó.

No perfil dos solos da área há uma predominância dos Neossolos Litólicos Eutróficos e dos Luvissolos Crômicos Órticos. A Serra de Santana se destaca pelo solo Latossolo Amarelo Distrófico. Dessa forma, o subíndice de pedologia (Figura 5B) apresenta variabilidade mais alta em termos de vizinhança, pois de uma quadrícula para outra o valor chega a variar 4 números.

Isso se deve não à diversidade de perfis pedológicos, mas à forma de variação desses solos em mapa. Ainda assim, se constitui num componente fundamental do índice de geodiversidade da região.

A região do Seridó potiguar é reconhecida pelo seu potencial mineiro, explorado há, pelo menos 70 anos, com a instalação das primeiras minas de scheelita, por exemplo. O mapa de ocorrências minerais comprova essa afirmação, mostrando ocorrências de 29 diferentes produtos, como Água-Marinha, Ouro, Berilo, Caulim, Granada, Quartzo, Turmalina, além de extração de rochas ornamentais e outras. Foram diferenciadas ocorrências simples de depósitos.

$\mathrm{O}$ subíndice relativo às ocorrências minerais (Figura 6A) possui valores mais altos nas porções sul e centro-leste do Geoparque, expressando a diversidade de minerais de interesse econômico nestas regiões da área estudada. Como forma de diferenciação entre simples ocorrências minerais e depósitos já identificados, foi definido o valor de 0,5 para cada ocorrência simples e de 1,0 para depósito, o que gerou subíndices de ocorrências minerais variando de 0 a 6 .

A partir do somatório de todos os subíndices obtidos, chegou-se ao índice de geodiversidade do Geoparque Aspirante Seridó de acordo com o método de Pereira et al. (2013), que é apresentado na Figura 6B.

O resultado da soma dos subíndices foi interpolado e classificado, obtendo-se um mapa coroplético para o índice de geodiversidade (Figura 7), com cinco classes, de acordo com os valores do índice obtidos: muito baixo (1-3), baixo (3-6), intermediário (6-9), alto (9-12) e muito alto (12-14). 

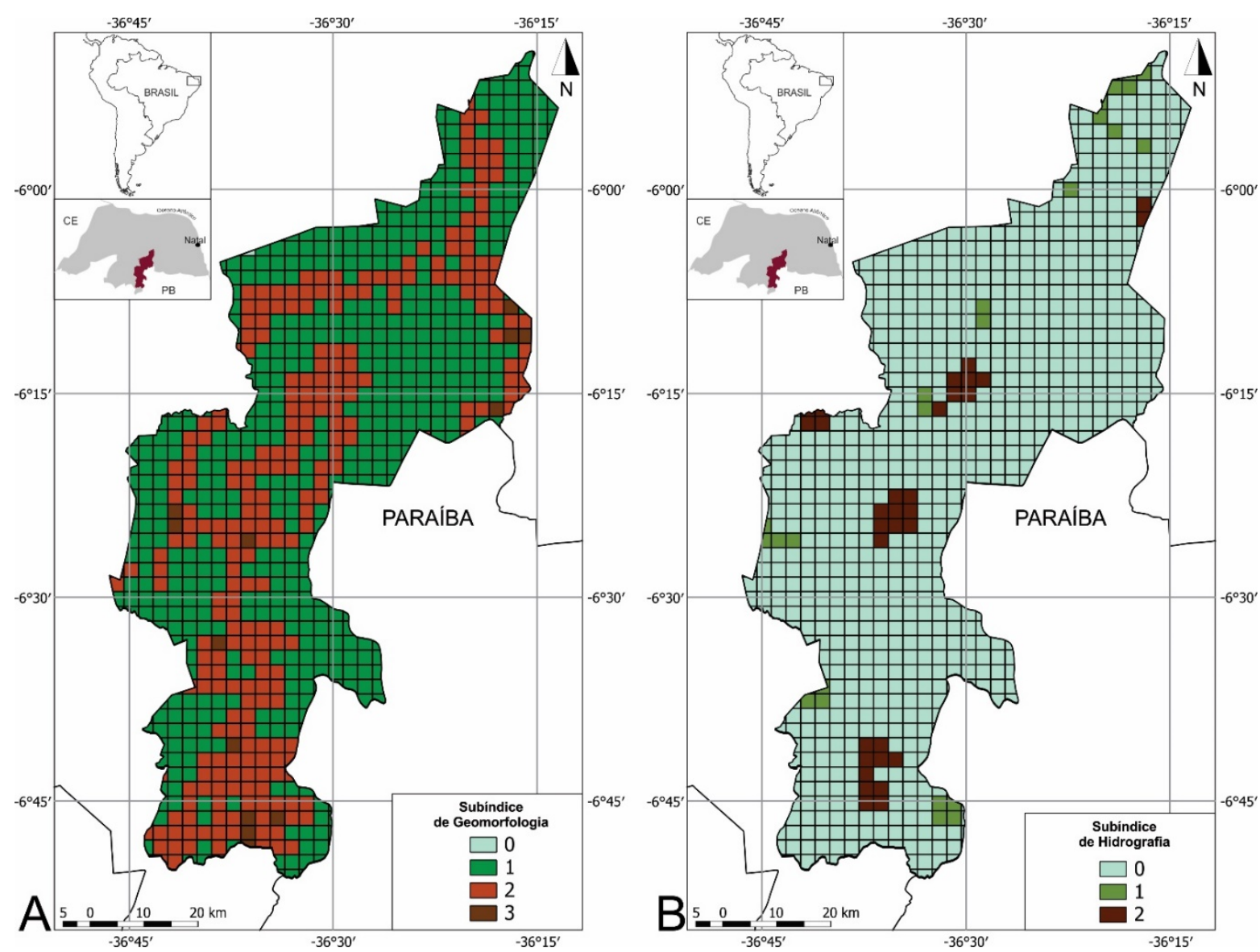

Figura 4 - Mapas de subíndice de geomorfologia (A) e subíndice de hidrografia (B).

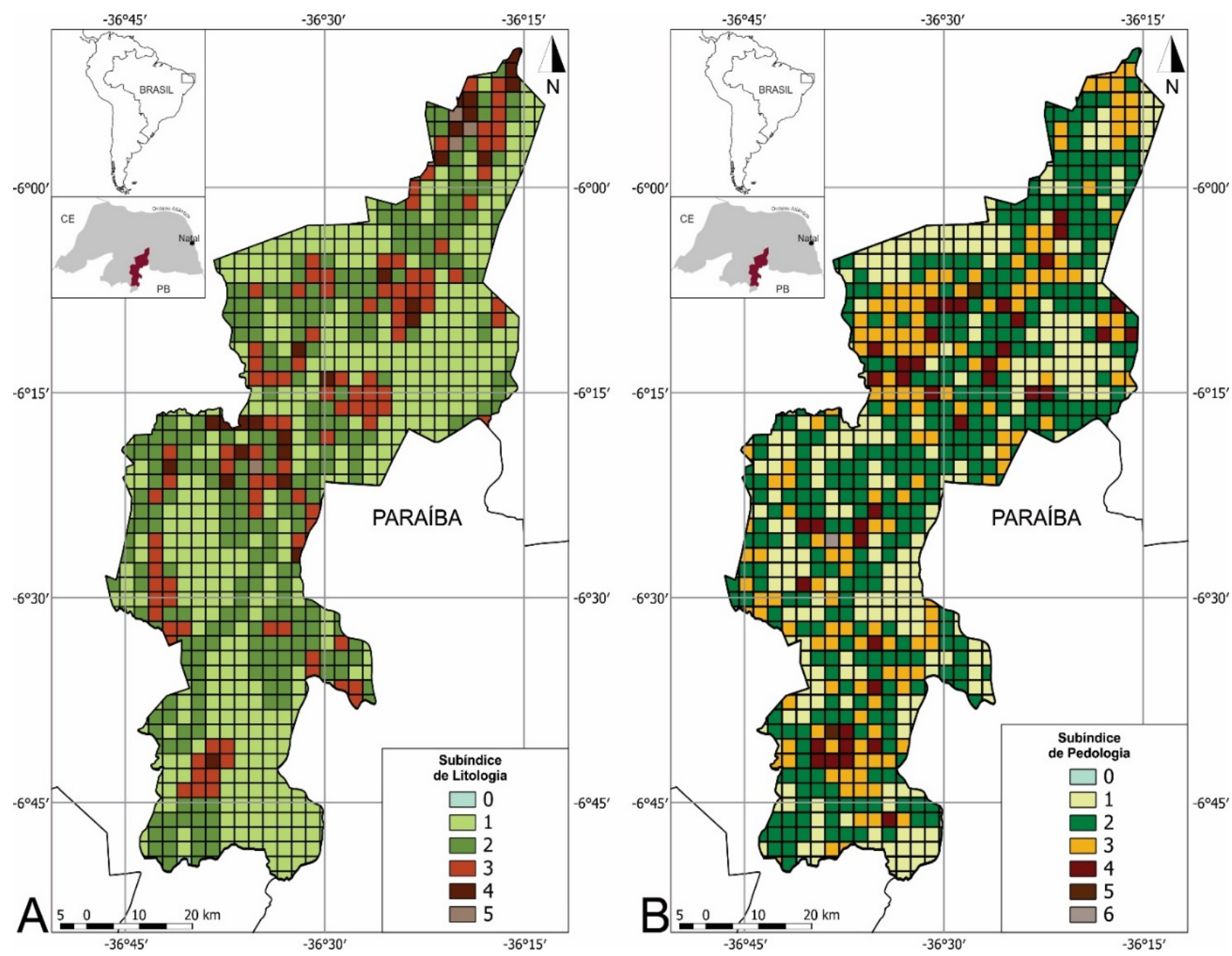

Figura 5 - Mapas de subíndice de litologia (A) e subíndice de pedologia (B).

São Paulo, UNESP, Geociências, v. 39, n. 3, p. 727 - 737, 2020 
Os valores médios e altos de geodiversidade estão localizados em concentrações no Geoparque Aspirante Seridó: nos extremos norte e sul da área, nos limites da Serra de Santana, numa pequena área do centro-leste e numa faixa

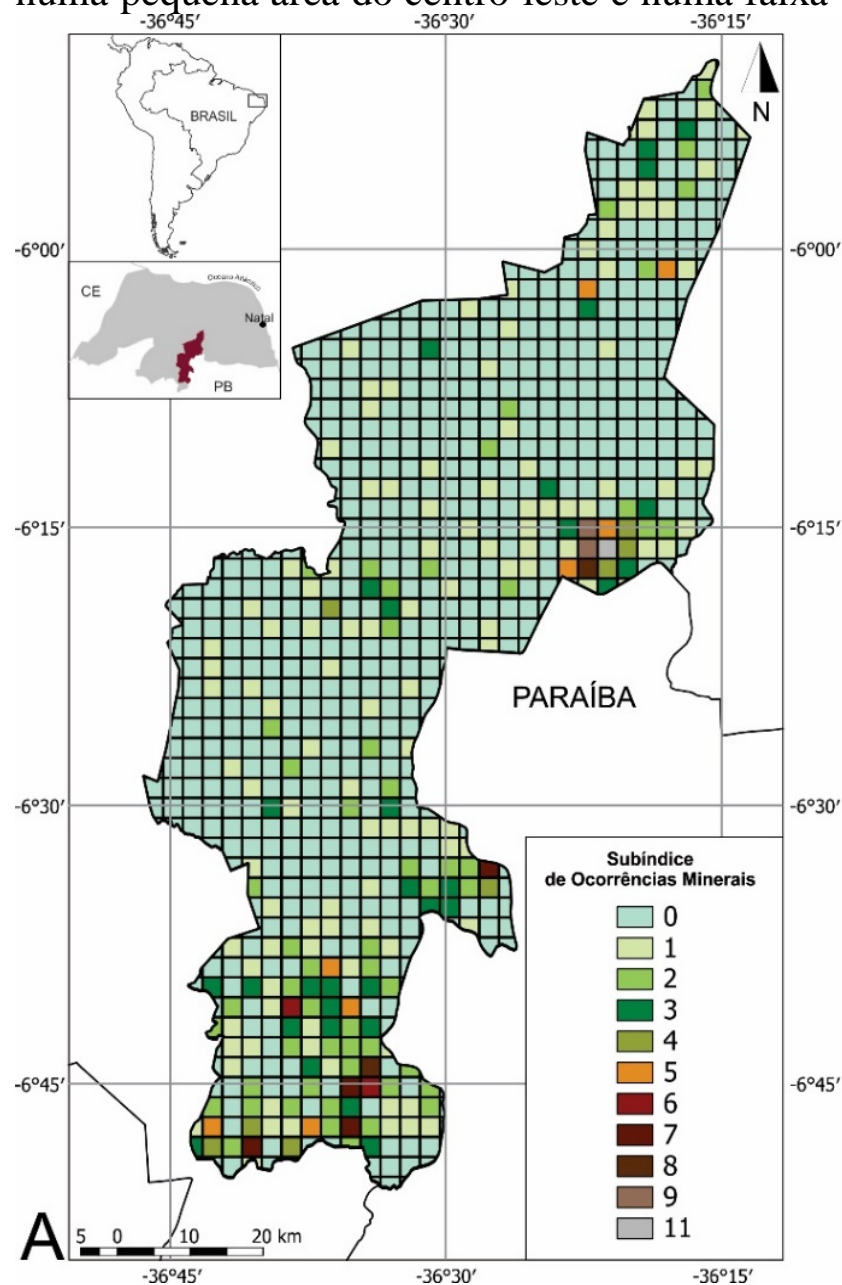

Figura 6 - Mapas de subíndice de ocorrências minerais (A) e índice de geodiversidade (B). central.

Observa-se uma boa correlação dos 21 geossítios com regiões de índices intermediários a muito altos, o que denota a representatividade destes sítios sobre a geodiversidade do território

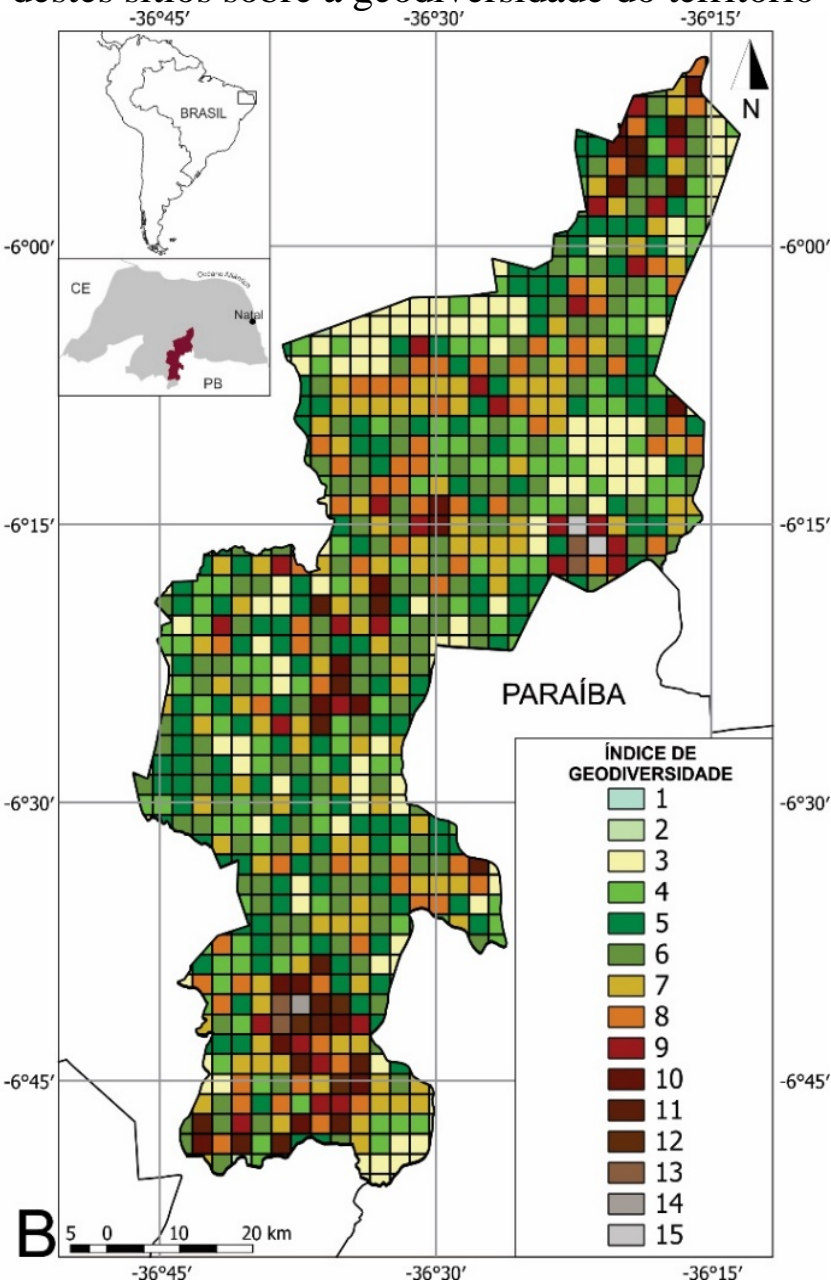

A partir dos resultados obtidos pela aplicação do método, pode-se apresentar uma análise quantitativa da avaliação realizada, relacionando os índices obtidos com ocorrências encontradas na região estudada.

Um exemplo de área de geodiversidade alta é a porção central do Geoparque Aspirante Seridó (Figura 8), em que são encontrados corpos de granito inequigranulares de granulometria média a grossa, compostos, essencialmente por Kfeldspato, plagioclásio, quartzo, biotita, anfibólio e minerais opacos.

As rochas graníticas estão associadas com a Suíte Intrusiva Itaporanga, ou Plúton Totoró, correlato ao Ediacarano. Nesta região são encontrados diversos enclaves de rochas dioríticas, além de diques de pegmatito em diferentes direções e dimensão. São observadas, ainda, diversas estruturas de deformação rúptil, como juntas e falhas, bem marcadas pelo deslocamento dos veios.

Uma área de geodiversidade avaliada com índice intermediário encontra-se no limite sudeste, na divisa com o estado da Paraíba. Nesta região ocorrem feições de cânions, modeladas pela erosão fluvial do Rio Picuí, esta área é conhecida como Cânions dos Apertados (Figura 9).

A principal litologia encontrada é o quartzito da Formação Equador, constituído predominantemente por quartzo, mas que apresenta ainda micas (muscovita e biotita) e alguns minerais máficos. A rocha foi gerada pelo metamorfismo de protólitos sedimentares e apresenta a preservação de estruturas da sedimentação e estratificações, ainda que dobradas. Ocorrem também alguns diques de pegmatito de espessuras variadas, cortando o quartzito, chegando a atingir níveis métricos. A rocha é tipicamente composta por K-feldspato, 
quartzo, biotita e turmalina.

Índice baixo de geodiversidade foi identificado sobre a região da Serra de Santana, no limite noroeste da área de estudo. Esta porção da área é caracterizada por um terreno aplainado (Figura 10), com predominância de sedimentos e rochas sedimentares de granulometria média a grossa correlata à Formação Serra do Martins.

A partir da avaliação quantitativa e a sua correlação com os geossítios do Geoparque Aspirante Seridó, observa-se que a maioria destes está localizada em áreas de índices altos de geodiversidade, são, portanto, excelentes representantes da diversidade abiótica na região, o que justifica, cientificamente, a necessidade de conservação destes locais. Ainda, a área centroleste foi identificada com índice alto de geodiversidade, porém ainda não possui um geossítio inserido no Projeto. Portanto, é essencial a definição de um local de interesse geológico nesta região de forma que este índice seja também compreendido.

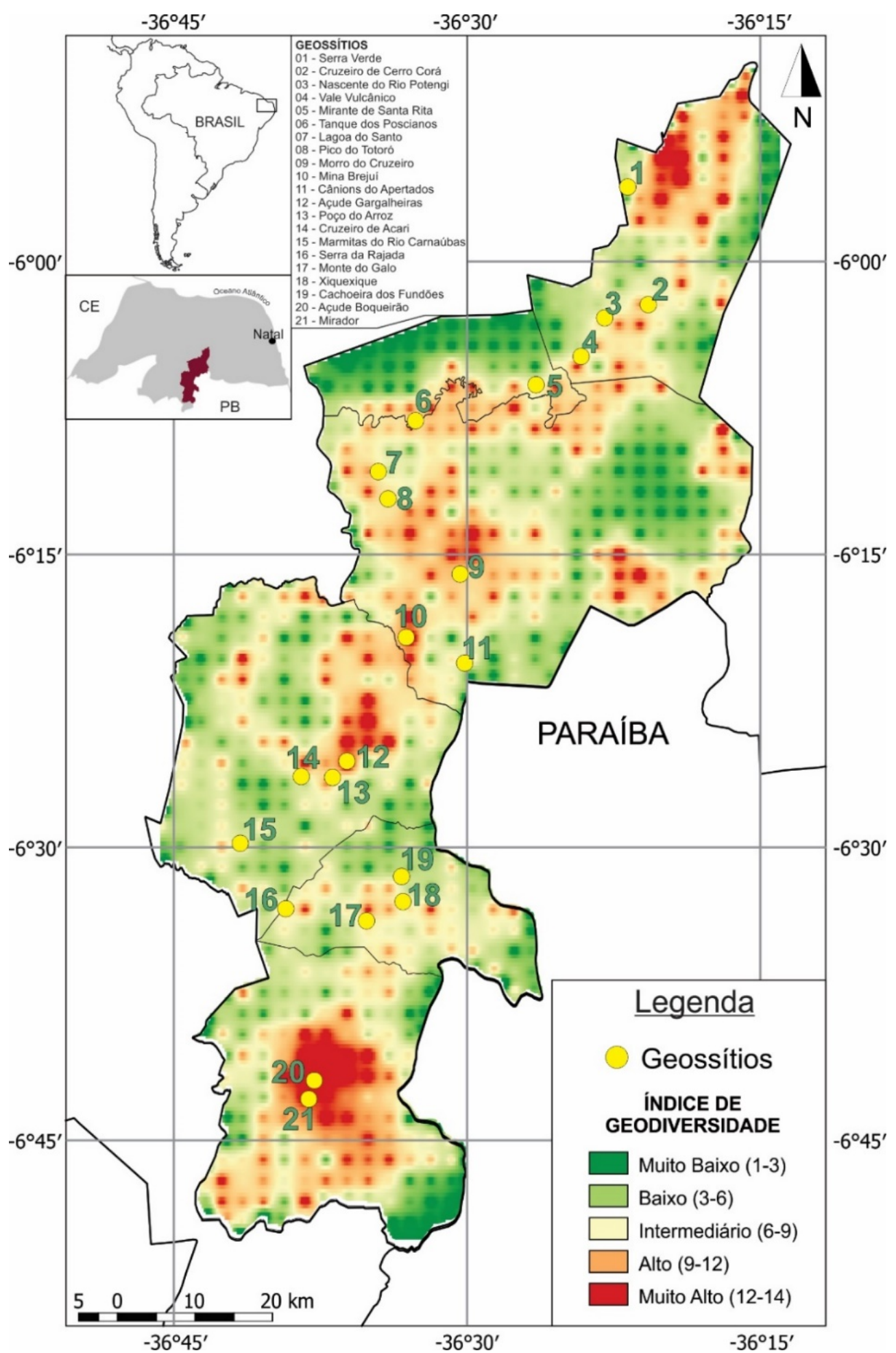

Figura 7 - Mapa de índice de geodiversidade classificado. 


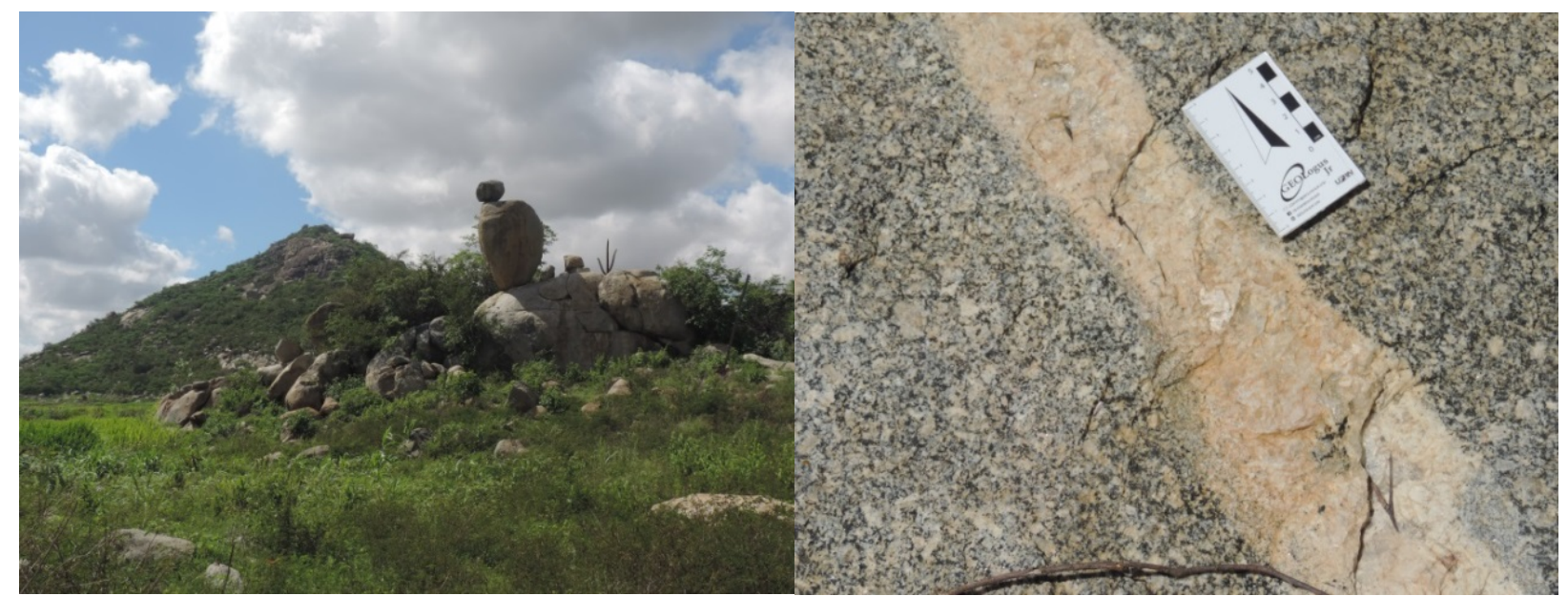

Figura 8 - Fotos da região do Pico do Totoró, na parte central da área de estudo, identificada por índice de geodiversidade alto. Fotos: Matheus Lisboa.

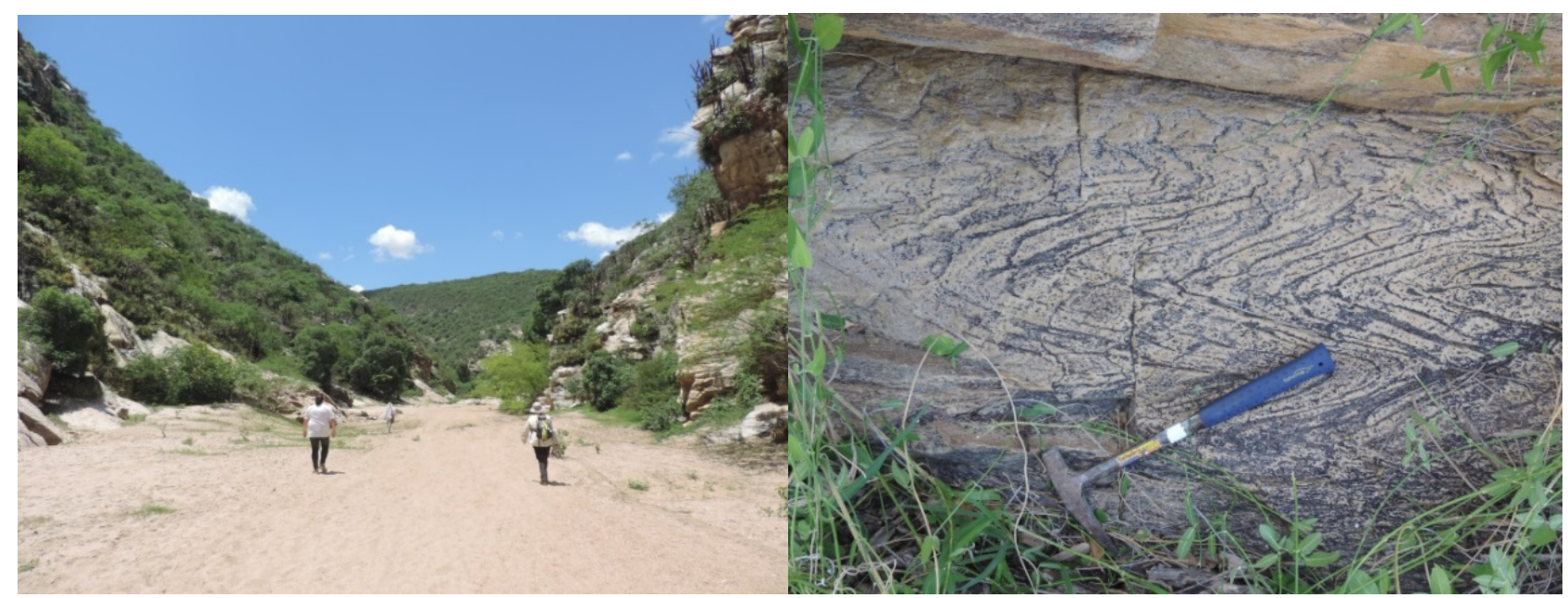

Figura 9 - Fotos da região dos Cânions dos Apertados, no limite sudeste da área de estudo, identificada por índice de geodiversidade intermediário. Fotos: Matheus Lisboa.

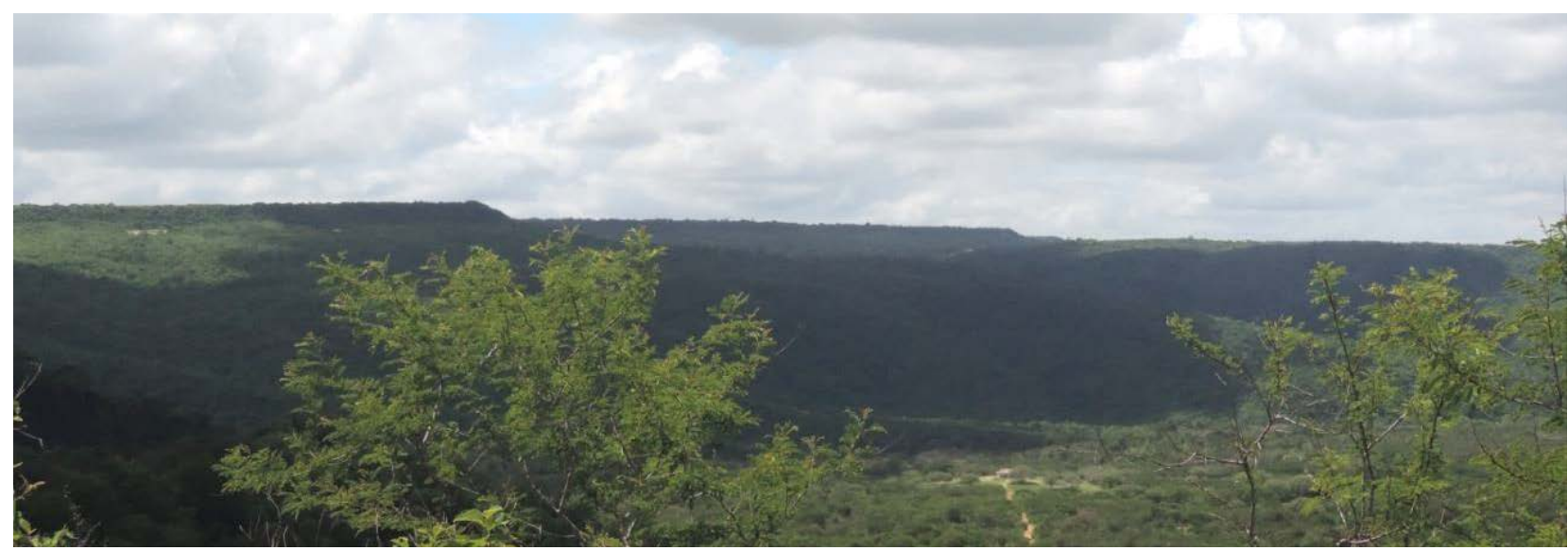

Figura 10 - Foto que apresenta o relevo aplainado do topo da Serra de Santana, uma região de índice de geodiversidade baixo. Foto: Matheus Lisboa.

\section{CONSIDERAÇÕES FINAIS}

O Geoparque Aspirante Seridó apresenta um forma quantitativa, através do uso do notável patrimônio geológico, representado por geoprocessamento. A definição de um grid diferentes elementos da geodiversidade no regular sobre os dados cartográficos utilizados interior do Rio Grande do Norte. A análise da apresentou diferentes subíndices de diversidade abiótica na região é fundamental geodiversidade que, ao serem somados, para elencar os principais locais de ocorrência da resultaram no mapa de índice de geodiversidade geodiversidade. Isto é possível de ser feito, de do Geoparque Aspirante Seridó. 
Pôde-se observar algumas áreas em que o índice é intermediário a muito alto, sendo essas áreas consideradas, portanto, prioritárias na definição de ações de conservação da natureza. São áreas relacionadas à alta diversidade dos elementos analisados: litologia, geomorfologia, pedologia, hidrografia e ocorrências minerais. O resultado cartográfico também apresentou boa correlação com os geossítios já definidos na área, o que reforça a importância desses locais.

Também foi possível observar áreas de geodiversidade elevada que ainda não possuem geossítios inventariados no âmbito do Geoparque Aspirante Seridó, informação que pode ser utilizada como norteadora nos próximos estágios de campo no desenvolvimento da proposta.

Ainda, toda a metodologia empregada neste trabalho foi efetivada através do uso de softwares livres, o que reforça a possibilidade de uso desse tipo de ferramenta nos estudos das geociências, diminuindo custos e atingindo um maior número de possíveis usuários.

\section{AGRADECIMENTOS}

O presente trabalho foi realizado com apoio da Coordenação de Aperfeiçoamento de Pessoal de Nível Superior - Brasil (CAPES) - Código de Financiamento 1696250. O autor Matheus Lisboa gostaria ainda de agradecer a todos que fazem o Museu Nacional e o Programa de Pós-Graduação em Geociências (UFRJ) pelo apoio sempre disposto, mesmo no momento em que a instituição se encontra.

\section{REFERÊNCIAS}

ALMEIDA, F.F.M.; HASUI, Y.; BRITO NEVES, B.B.; FUCK, R.A. Províncias Estruturais Brasileiras. In: SIMPÓSIO DE GEOLOGIA DO NORDESTE, 8, 1977, Campina Grande, Atas.. Sociedade Brasileira de Geologia, 1977, p. 363-391.

ANGELIM, L.A.A.; NESI, J.R.; TORRES, H.H.F.; MEDEIROS, V.C.; SANTOS, C.A.; VEIGA JR, J.P.; MENDES, V.A. Geologia e Recursos Minerais do Estado do Rio Grande do Norte - Escala 1:500.000. Recife: CPRM - Serviço Geológico do Brasil, 119 p., 2006.

ARAÚJO, A.M. \& PEREIRA, D.I. Mapeamento do Potencial dos Recursos Hídricos e da Geodiversidade do Estado do Ceará (Brasil) com base em SIG. Comunicações Geológicas, v. 103, n. 1, p. 99-105, 2016.

ARRUDA, K.E.C. \& BARRETO, A.M.F. Índice de Geodiversidade do Município de Araripina - PE, Brasil. Estudos Geológicos, v. 25, n. 1, p. 103-117, 2015.

DINIZ, M.T.M. \& OLIVEIRA, G.P. Compartimentação e Caracterização das Unidades de Paisagem do Seridó Potiguar. Brazilian Geographical Journal, v. 6, n. 1, p. 291-318, 2015.

DINIZ, M.T.M.; OLIVEIRA, G.P.; MAIA, R.P.; FERREIRA, B. Mapeamento Geomorfológico do Rio Grande do Norte. Revista Brasileira de Geomorfologia, v. 18, n. 4, p. 689-701, 2017.

IBGE-Instituto Brasileiro de Geografia e Estatística. Cidades@ Disp. em: https://cidades.ibge.gov.br/. Acessado em 25mai2020.

IDEMA-Instituto de Desenvolvimento Econômico e Meio Ambiente do Rio Grande do Norte. Atlas para a Promoção do Investimento Sustentável no Rio Grande do Norte. Natal: Opção Gráfica Editora, 186 p., 2009.

INMET-Instituto Nacional de Meteorologia, Normais Climatológicas do Brasil. Disp.em: http://www.inmet.gov. br/portal/index.php?r=clima/normaisClimatologicas. Acessado em 28jul 2018.

JAČKOVA, K. \& ROMPORTL, D. The Relationship Between Geodiversity and Habitat Richness in Sumava National Park and Krivoklatsko Pla (Czech Republic): a Quantitative Analysis Approach. Journal of Landscape Ecology, v. 1, n. 1, p. 23-38, 2008.

KOZLOWSKI, S. Geodiversity. The concept and scope of geodiversity. Przeglad Geologiczny, v. 52, n. 8, p. 833-837, 2004.

MEDEIROS, J.L. Práticas Turísticas em Geossítios: um Avaliação Ambiental no Projeto Geoparque Seridó-RN. Natal, 2015. 167 p. Dissertação (Mestrado em Turismo) Programa de Pós-Graduação em Turismo, Universidade Federal do Rio Grande do Norte.
NASCIMENTO, M.A.L. \& FERREIRA, R.V. Geoparque Seridó (RN): Proposta. In: SCHOBBENHAUS, C. \& SILVA, C.R. (Orgs) Geoparques do Brasil: propostas - V. 1. Rio de Janeiro: CPRM - Serviço Geológico do Brasil, p. 361-416, 2012.

PEREIRA, D.I.; PEREIRA, P.; BRILHA, J.; SANTOS, L. Geodiversity Assessment of Paraná State (Brazil): An Innovative Approach. Environmental Management, v. 52, p. 541-552, 2013.

REYNARD, E.; FONTANA, G.; KOZLIK, L.; SCAPOZZA, C. A method for assessing «scientific» and «additional values» of geomorphosites. Geographica Helvetica, v. 62, p. 148-158, 2007. RODRIGUES, S.C. \& BENTO, L.C.M. Cartografia da Geodiversidade: Teorias e Métodos. In: GUERRA, A.J.T. \& JORGE, M.C.O. (Orgs) Geoturismo, Geodiversidade, Geoconservação: abordagens geográficas e geológicas. São Paulo: Oficina de Textos, p. 137-162, 2018.

SANTOS, D.S.; MANSUR, K.L.; GONÇALVES, J.B.; ARRUDA JR, E.R.; MANOSSO, F.C. Quantitative assessment of geodiversity and urban growth impacts in Armação dos Búzios, Rio de Janeiro, Brazil. Applied Geography, v. 85, p. 184-195, 2017.

SERRANO, E. \& RUIZ-FLAÑO, P. Geodiversity. A theoretical and applied concept. Geographica Helvetica, v. 62, p. 140-147, 2007. SILVA, J.P.; RODRIGUES, C.; PEREIRA, D.I. Mapping and Analysis of Geodiversity Indices in the Xingu River Basin, Amazonia, Brazil. Geoheritage, v. 7, n. 4, p. 337-350, 2015.

SILVA, M.L.N. Serviços Ecossistêmicos e Índices de Geodiversidade como Suporte da Geoconservação no Geoparque Seridó. Rio de Janeiro, 2018. 177 p. Dissertação (Mestrado em Geociências) - Museu Nacional, Universidade Federal do Rio de Janeiro.

ZWOLINSLI, Z.; NAJWER, A.; GIARDINO, M. Methods for Assessing Geodiversity. In: REYNARD, E \& BRILHA, J. (Eds) Geoheritage: Assessment, Protection and Management. UK: Elsevier, p. 27-52, 2018. Aceito para publicação em 11 de agosto de 2020 